Journal of Social Sciences 6 (2): 206-211, 2010

ISSN 1549-3652

(C) 2010 Science Publications

\title{
Aquaculture Industry Potential and Issues: A Case from Cage Culture System Entrepreneurs: Suggestions for Intensification of Aquaculture Industry
}

\author{
${ }^{1}$ A.N. Ahmad Faiz, ${ }^{3}$ I. Khairuddin, ${ }^{2}$ U. Jegak, ${ }^{2}$ M.S. Hayrol Azril and ${ }^{2}$ L.S. Jeffrey \\ ${ }^{1}$ Department of Agriculture Technology, Faculty of Agriculture, University Putra Malaysia \\ ${ }^{2}$ Laboratory of Rural Advancement and Agriculture Extension, \\ Institute for Social Science Studies, University Putra Malaysia \\ ${ }^{3}$ Department of Professional Development and Continuing Education, \\ Faculty of Education, University Putra Malaysia, Malaysia
}

\begin{abstract}
Problem statement: Cage culture has become a popular aquaculture system nowadays. In the recent statistics provided by DOF, the cage culture system has generated almost USD $400 \mathrm{~m}$ (RM $1.39 \mathrm{~b})$ of income per year. In order to further intensify this economic activity the Ministry of Agriculture and Agro-based Industry (MOA) through the DOF has zoned the aquaculture industry via Aquaculture Industry Zone (ZIA) Programs throughout Malaysia. Cage culture system seems to have the ability to be a catalyst in enhancing the economy level of local people but it is well known that certain problems must be overcome first before the potential can be clearly seen. Thus the main focus of this study is to clarify all the potentials and problems faced by the cage culture system entrepreneurs in running their aquaculture activity. Approach: The research approach for this study was a qualitative case study that provided an in-depth description of potentials and issues in aquaculture industry in the district of Kuala Pahang, Malaysia. Data was gained using a Focus Group Discussion (FGD) among the cage culture system entrepreneurs guided by an interview guide. A total of 10 cage culture entrepreneurs were selected as the FGD members. The questions served as a guide, but allowed respondents freedom and flexibility in their answers. The findings were in descriptive analysis. Results: The cage culture system was found to provide better income that lead to a higher quality of life for the entrepreneurs, positive intangible values existed among the entrepreneurs; experiences have taught them to become self independent. There were problems identified such as no independence in selecting the fingerlings, environmental problems seem to burden them, unstable pellet price, no official agreement between them and the government emphasizing the portion of the river is given to them for running their business and lot of bureaucracies that the entrepreneurs need to face. Conclusion/Recommendations: Based on the results gained, it can be concluded that even though cage culture industry proved to enhance the level of income and quality of life, a number of problems must be overcome first to further enhance their level of income and quality of life. Therefore, it is a need that the related agencies to provide more financial supports help to solve the environmental problems and further develop their administration aspects to reduce issues such as bureaucracy and official agreement.
\end{abstract}

Key words: Cage culture system, entrepreneurs, potentials and problems

\section{INTRODUCTION}

Agriculture is not a second class business anymore. As the third engine of growth, its importance in revitalizing the Malaysian economic cannot be denied. In the Ninth Malaysian Plan (9MP) (2006-2010) Malaysian agriculture has been revitalized and used as an impetus to boost the economy sector. Thus, this would be happened again in the year 2010 where the
Malaysian Government has announced that almost USD $2 \mathrm{~b}$ has been allotted to further strengthen the agriculture sector. In the recent days agriculture has been recognized as one of effective mechanism to eradicate poverty. This is not surprising as people who are switched into agriculture are found to have more income and higher quality aim to bring higher earnings and to enhance the socio-economic level of the poor people. High Impact Programs (HIP) such as

Corresponding Author: A.N. Ahmad Faiz, Department of Agriculture Technology, Faculty of Agriculture,

University Putra Malaysia, Malaysia 


\section{J. Social Sci., 6 (2): 206-211, 2010}

Aquaculture Industry Zone or locally known as HIPZIA, Permanent Food Production Parks (TKPM) and Agropolitan, all have been initiated to increase the people's quality of life as well as socio-economic conditions.

Aquaculture is one of the important branches in agriculture. Recent statistics provided by the Department Of Fisheries Malaysia (DOF) has expected that aquaculture industry will generate almost USD 400 m (RM 1.39 b) of income per year. This huge amount has depicted the potential of this industry to be developed. Cage culture is one of aquaculture systems that have a lot of potentials and can be further developed in the future. In the recent statistics provided by DOF, the cage culture system has produced more than 22,000 tons of fish per year and the value is about USD $106 \mathrm{~m}$ (RM $371 \mathrm{~m})$ per year. In order to further strengthen this business, the Ministry of Agriculture and Agro-based Industry (MOA) through the DOF has developed Aquaculture Industry Zone (ZIA) Programs throughout Malaysia. The program aims: (1) to create permanent areas for Aquaculture Industry Zone; (2) to increase the production of fish in line with the goal of Balance of Trade (BoT) plan; (3) to increase the net income of aquaculturists to at least USD 850 per month; (4) to ensure the production of fish and fish products that are of high quality and safe for consumption; (5) to increase private sector participation through the provision of ZIA areas, infrastructure and Department Delivery System (DDS) and (6) to create a chain of efficient aquaculture fish production areas. Preparation of huge budget and systematic program planning will draw a bigger potential to the cage culture industry and this must be manipulated wisely by the relevant parties.

Aquaculture has a lot to offer. It is a sector that has the ability to reduce employment problem in most country of the world (Boi, 2008; Muir, 2005; Bardach, 1997). Unemployment is seems to be crucial especially among the university graduates. The problem is found to increase every year. Therefore, aquaculture is an alternative because it can provide a better solution to overcome this particular problem. As the unemployment problem can be reduced, this will result to more people having job and stable income (Sapovadia, 2004). A positive part brought by the aquaculture sector on employment and income, will do have impacts on education. Training and courses which made compulsory to be attended will enhance skills and knowledge to those who involved. In a study completed by Karmokolias (1997) regarding to Madagascar trained biologists specializing in shrimp culture and provided training to its laboratory personnel. Besides, workers in the company also received on-job training from participating in regular sessions to learn about proper health and occupational practices. Instead of supplying basic products for home uses and generating sales revenues, aquaculture can double the profits and produce tax and export revenues. This industry also can be used as a tool to alleviate poverty in the community (Choo, 2008). Besides, it has the ability to significantly reduce the gap between fish demand and supply. The productivity of the aquaculture industry will fill the gap of fish supply, thus it can meet the fish demand which can expedite the country's economic development (Department of Fisheries Malaysia, 2007; Jamaludin, 2004; Brugere and Ridler, 2004).

Aquaculture would strengthen the stability of domestic food supplies by branching out the aquatic products. This will intensify the country's' resistance to some transitory shocks that may have negative impacts on food security such as the 2007 economic crisis for example. In that year, global community has been affected by the significant increase of the paddy price which burdens them. Likewise, by securing incomes and jobs of households and individuals employed in the sector and related activities, aquaculture can increase the households' resistance against transitory food insecurity. Aquaculture through the fishes produces will offer enormous amount of nutrition which in turn will produce healthier community (Tacon, 2001).

The above phenomenon is noteworthy to the economic development but despite all of the potentials mentioned, it is well known that certain problems must be overcome first before the potential can be clearly seen. Thus the main focus of this study is to clarify all the potentials and problems faced by the cage culture entrepreneurs in running their aquaculture activity and hopefully suggestions made based on the findings can aid the pertinent agencies to further intensify the aquaculture industry in Malaysia.

\section{MATERIALS AND METHODS}

The research approach for this study was a qualitative case study that provided an in-depth description of potentials and issues in aquaculture industry in the district of Kuala Pahang, Malaysia. Data was collected using a Focus Group Discussion (FGD) among the cage culture system entrepreneurs guided by an interview guide. The FGD consists of 10 members. The questions served as a guide, but allowed respondents freedom and flexibility in their answers. The findings were in descriptive analysis. 


\section{J. Social Sci., 6 (2): 206-211, 2010}

\section{RESULTS}

The potentials: After almost nine years the entrepreneurs involved in aquaculture industry, their business is getting more stable and they also manage to increase their income. The entrepreneurs' leader has told that in the year 2010, they expected to culture about 200,000 brackish water giant sea perch and tilapia fingerlings. With these fingerlings they expected to increase their income and provide a better living. They also have been offered by a related agency incentives based on their productivity.

Regarding to their achievements in the cage culture activity, they have bring extra income for their villagers. The fishing net makers for instance, they can get some extra income by selling the fishing net for the entrepreneurs to make cages for their cultures. The benefits also drained to the coastal fishermen because the entrepreneurs did buy their fish as an alternative fish feed instead of expensive pellet for their cultures.

There are positive intangible values indeed existed among the entrepreneurs. They have shown that they were highly self-confident, self-independent and sense of belonging to each other in running their business activity. They proved that they have succeeded the mentorship program, where the experienced entrepreneurs became mentors to the new entrepreneurs and educate them. They also have proved that through this program, they manage to attract people to join them and the most interesting part is that they manage to attract younger generations. It was noted that one third of the entrepreneurs were youth.

They agreed that experiences have taught them to become self-confident and self-independent. Initially, they started their business in the sense of "try and error" approach. They started their business with their own money without help either from the government or private agencies, until they succeed. It is also interesting to know that they have developed their own medicine to mediocre most of the infected cultures. Their traditional medical knowledge has brought them to try and they agreed that it was an effective alternative medicine.

The issues: Currently, the entrepreneurs have received subsidized fingerlings and wood for their cages from a government agency. Instead of bringing smile on their faces, they bring headache to them. These subsidized fingerlings and wood are not at good quality. They have no choice, only to accept. They have emphasized that the fingerlings' quality would affect their productivity. They have proved that the death rate of the fingerlings can be up to $50 \%$ during the development stages, the responsible agency seem facing difficulties in providing the type of fingerlings that they want. Pertinent to this, they also have no independence in choosing the type of wood for their cages. There have no choices other than using their own money to buy the required wood.

The price for the pellet seems to be one of the major problems. They don't have enough financial support for this. The price has doubled since two years back. There is lack of "synergy" from the responsible agencies in helping them in their business. Besides require extra cash to buy the pellet, they also need the financial support to get fine woods for constructing their cages, quality cage nets and fingerlings.

Among the major concern of the entrepreneurs is regarding the protection of their business area from other bigger investment. Meaning that there is no official agreement between them and the government emphasizing the portion of the river is given to them for running their business. They said this is important since they were afraid that other major business will come and take over their places.

Environmental problems seem to burden them. There are some identified factories that released unknown materials to the river. In addition, the polluted water from the nearest highway construction found to pollute the river. Up to this stage they said that their fish is not affected, but they afraid their fish will be affected for a long term period. They also needed assistance from the related agencies regarding protection from the fish diseases. It is true that they have invented and adapted their own traditional mediocre for some of the diseases, but according to them, it only managed to reduce the effect and not fully mediocre it.

There were a lot of bureaucracies that the entrepreneurs need to face. This brought some difficulties to them. First, it delays the process of their business especially on the payment process. They frequently set meetings with the government officers and there a lot of important decisions have been made but due to the bureaucracy process, they have found that it is hard to bring the decisions to the top authority. Related to this, they also emphasized on the importance of field training and practices rather than attending the theory seminars or courses. Some of the theory courses are made compulsory to be attended by them. They noted that on-field training from the senior entrepreneurs or their mentor is more effective than attending the theory courses by the related agencies. They said this because not too many knowledge from the courses or seminar can be applied on the real situation. The other problem related to the bureaucracy is concerning the incentives offered to them. Majority of them reluctant to claim the incentives offered due to 


\section{J. Social Sci., 6 (2): 206-211, 2010}

lot of forms are needed to fill. They claimed that these forms are too complicated to fill.

\section{DISCUSSION}

Generally, the empirical study found that there are a lot of potentials in cage culture system of aquaculture industry in Malaysia. A significant of the phenomena was that, previously the cage culture system has produced more than 22,000 tons of fish that is equivalent to USD $400 \mathrm{~m}$ (RM $1.39 \mathrm{~b}$ ). The industry would be expected to be increased in the future.

An important caveat to this study relates to the issues raised and the potential of cage culture system of aquaculture industry in Malaysia. The study has found four main potentials to the industry: (1) better income; (2) increase socio-economy; (3) cooperativeness and (4) experiences. Instead of potentials, issues also indicated in the study: (1) selection of fingerings and wood material; (2) environmental; (3) medicine; (4) pellet price; (5) business protection; (6) bureaucracy and (7) training effectiveness.

In the longer-run, for efficient, consideration should be given to related agencies to provide more focus on the entrepreneurs' development because as a high impact program that with the aim to fulfill the national fish supply and demand, it should be the main focus from the related agencies. Similarly, the productivity of the aquaculture industry will fill the gap of fish supply, thus it can meet the fish demand which can expedite the country's economic development (Department of Fisheries Malaysia, 2007; Jamaludin, 2004; Brugere and Ridler, 2004).

Regarding to the phenomenon, a synergistic effect from the related agencies should be put forth. The entrepreneurs have their power to implement. With help from related agencies, hopefully will provide better income to the entrepreneurs and increase their productivity. In addition, bureaucracies in the related agencies also need to reduce. Referring to previous study by Feeney and Davis (2009) and Moss (2005), bureaucracy is one of the impetuses that will reduce the productivity. With this regard, the related agencies also need to know what the entrepreneurs' need to be considered.

Even though the program is deemed to "bottomup" approach in planning the program, some technical aspect such as in selecting fingerlings and wood. This is because the entrepreneurs know better about progress on the ground. Similarly, Cervero and Wilson (1994) indicate that in theorising the programme planning, the social setting should take into account. The social setting is often based on the power and influence of the programme planners. According to Yang et al. (1998), they suggested that effective planner should completely understand the planning process and is able to use a variety of power and influence tactics according to situations.

\section{CONCLUSION}

The responsible agencies such as the Federal Agriculture Marketing Authority (FAMA) probably can assist them to find a proper marketing channel. They indeed need the help in getting better price for their fish because the price offered to them is still considered low compare to the current price in the market. One of the potential marketing channels according to the entrepreneurs is the Halal Hub (Halal Market in Malaysia) or the hypermarket such as Mydin, Giant, Tesco and Carrefour. Perhaps through these channels, it will create better marketing networks with control input price. This hopefully will reduce the cost of the middle man which burdens them.

The mentor program that established in this area should be practiced in all aquaculture areas throughout Malaysia. Supervisions from experienced person on the new person are indeed an effective way of learning and training process and this has been proved to increase the productivity number and quality (Prihatin, 2004).

The responsible agencies should have a mechanism to create more systematic planning to help the entrepreneurs. Systematic planning is indeed an important key for any organization success as stressed by Garzon (2009); Brinckmann et al. (2008) and Goodwin (1988). This perhaps will able to control the prices, one is one the fish itself and another one is one the pellet. The entrepreneurs have frequently repeated in the FGD that government should already establish a standard or siling price for different type of fish. The entrepreneurs face a lot of difficulties in getting a better price and they also have to pay the middle man cost which for them is reducing their profits a lot. From the FGD, they emphasized that the pellet price has significantly increased from the year 2006 until the current year without monitoring from the responsible agencies. More than 50\% increase recorded on the pellet price. Situation became worse when the economic crisis stroked in 2007 in which fuel price has increased. Pellet producers have made this reason to increase the pellet price. It is something beneficial to the entrepreneurs if some subsidies on the palet can be introduced. Related to this also, systematic planning also is perhaps to reduce the bureaucracy matters. Bureaucracy issues are hindering them in getting some of available potentials of this sector. 
It is interesting to know that this aquaculture business is managed to attract interest from the young generation. It was found that $30 \%$ of the entrepreneurs were among youth. This can be an indicator for the government on type of agriculture activity that can attract the youths' interests. It is suggested that promotion intensification on aquaculture business activity should be practiced among the youth. By doing this, it will ensure that this activity have adequate and quality backup generation.

Entrepreneurs should be given more freedom in choosing the type of fingerlings and wood for their business. Practically, they have already proved that the fingerlings given by the related agency seems to have high death rate compared to the fingerlings that they choose which have lower death rate. But to have their own choice of fingerlings and wood meaning that they have to invest on their own money and no financial support from the related agencies. Here, it is suggested that the responsible agency should play their role in assisting the entrepreneurs financially and let the entrepreneurs have their own choices of fingerlings and wood. Maybe, the responsible agency instead of providing the financial support, they can monitor the progress of the fingerlings and the wood quality. Here, they can know and become clearer regarding the actual situation on the ground.

\section{ACKNOWLEDGEMENT}

The study has been funded by the Fundamental Research Grant Scheme. The authors would like to express their sincere appreciation for all of the support provided.

\section{REFERENCES}

Bardach, J.E., 1997. Sustainable Aquaculture. Wiley and Sons, New York, ISBN: 9780471148296, pp: $1-14$.

Boi, N.V.Q., 2008. Aquaculture and Environmental Issues in the Region of Nai Lagoon, Ninh Hai District, Ninh Tuan Province, Vietnam. Scand Media Publisher, Bangkok, pp: 8-12.

Brinckmann, J., D. Grichnik and D. Kaspa, 2008. Should entrepreneurs plan or just storm the castle. A meta analysis on contextual impacting the business planning performance relationship in small firms. Bus. Ventur., 25: 24-40. DOI: 10.1016/J.JBUSVENT.2008.10.007

Brugere, C. and N. Ridler, 2004. Global aquaculture outlook in the next decades: An analysis of national aquaculture production forecast to 2030 . Food and Agriculture Organization of United Nations, FAO Fisheries Circular No 1001, pp: 47.
Cervero, R.M. and A.L. Wilson, 1994. Planning responsibly for adult education: A guide to negotiating power and interests. Adult Educ. Q., 46: 182. http://direct.bl.uk/bld/PlaceOrder.do?UIN=009522 $748 \&$ ETOC $=$ RN\&from $=$ searchengine

Choo, P.S., 2008. Asian women in the fisheries sector: Identifying issue providing solutions. Proceeding of the Regional Conference on Women in Fisheries, Dec. 2-4, Organized by SEAFish for Justice Networks, Hanoi, Vietnam, pp: 1-1.

Department of Fisheries Malaysia, 2007. Status of Fisheries Sector in Malaysia in 2007. http://www.dof.gov.my/c/document_library/get_fil e?uuid $=\mathrm{d} 33 \mathrm{bf} 6 \mathrm{ec}-8 \mathrm{ad} 8-4186-87 \mathrm{cf}-$

bbf72f059abc\&groupId=172176

Feeney, M.K. and L.D. Davis, 2009. Bureaucracy and public employee behavior: A case of local government. Rev. Public Person. Admin., 29: 311320. DOI: 10.1177/0734371X09333201

Garzon, M.D., 2009. A comparison of personal entrepreneurial competence between entrepreneurs and CEOs in the service sector. Serv. Bus., 1: 1-15. DOI: $10.1007 / \mathrm{s} 11628-009-0090-6$

Goodwin, C., 1988. I can do it myself training the service consumer to contribute to service productivity. Serv. Market., 2: 71-78. DOI: 10.1088/eb024745

Jamaludin, O., 2004. A Critical Appraisal of the Strategy and the Structure of the Fishermen Associations in Malaysia. http://www.unuftp.is/static/fellows/document/jamal 04prf.pdf

Karmokolias, I., 1997. Madagascar: Aquaculture de la Mahajamb. In: The Private Sector and the Development Five Case Studies, Leung, P.S., J. Muraoka, S. Nakamoto and S. Pooley, (Eds.). ISBN: 9789251060414, pp: 35-42.

Moss, S., 2005. Main effect of bureaucracy is to reduce productivity. Nature, 437: 308-311. DOI: $10.1038 / 4371089 \mathrm{c}$

Muir, J., 2005. Managing to harvest. Perspectives on the potential of aquaculture. Philosoph. Transport. R. Soc., 360: 191-218. DOI: 10.1098/rstb.2004.1572

Prihatin, D.R.B., 2004. Factors Influencing the Small Scale Entrepreneurs in Indonesia. In: Ongoing Themes in Psychology and Culture, Supratiknya, A., W.J. Lonner and Y.H. Poortinga (Eds.). International Association for Cross-Cultural Psychology, Melbourne, FL., pp: 651. 
Tacon, A.G.J., 2001. Increasing the contribution of aquaculture for food security and alleviation. Proceedings of the Conference on Aquaculture in the Third Millennium, Feb. 20-25, NACA, Bangkok, Thailand, pp: 63-72. http://www.fao.org/docrep/003/ab412e/ab412e30.h tm

Sapovadia, V.K., 2004. Fishermen cooperative: A tool for socio-economic development. Proceeding of the Conference of the International Institute of Fisheries Economics and Trade (IIFET), July 2030, Organized by IIFET, Tokyo, Japan, pp: 1-11.
Yang, B., R.M. Cervero, T. Valentine and J. Benson, 1998. Development and validation of an instrument to measure adult educators' power and influence tactics in program planning practice. Adult Educ. Q., 48: 227-244. 